\title{
Intelligent systems applied to buildings' management
}

\author{
R. Pereira \\ Instituto Politécnico de Lisboa (IPL), \\ Instituto Superior de Engenharia de \\ Lisboa (ISEL), Electrical, Energy and \\ Automation Department (ADEEEA) \\ LCEC - Low Carbon Energy Conversion \\ $R \& D$ Group \\ Lisbon, Portugal \\ rpereira@deea.isel.ipl.pt
}

\author{
F. A. Barata \\ Instituto Politécnico de Lisboa (IPL), \\ Instituto Superior de Engenharia de \\ Lisboa (ISEL), Electrical, Energy and \\ Automation Department (ADEEEA) \\ Lisbon, Portugal \\ fbarata@deea.isel.ipl.pt
}

\author{
C. Viveiros \\ Instituto Politécnico de Lisboa (IPL), \\ Instituto Superior de Engenharia de \\ Lisboa (ISEL), Electrical, Energy and \\ Automation Department (ADEEEA) \\ Lisbon, Portugal. \\ cviveiros@deea.isel.ipl.pt
}

\begin{abstract}
Energy efficiency in buildings are an important domain regarding its impact in the global energy consumption. Several efficiency measures are currently available, using different methodologies. In this paper an approach using intelligent systems is implemented through a smart controller able to automatically and efficiently manage building's energy. This smart controller uses Fuzzy Logic Control (FLC) as a decision maker and is supported by Artificial Neural Networks (ANN) used to forecast the building outside temperature. In addition, and in order to increase overall energy efficiency, renewable energies associated with a storage system are considered. For the designed smart controller implementation, a thermal house model is simulated using a MATLAB toolbox. In this paper emphasis is given to the building's Heating Ventilation and Air Conditioning (HVAC) control and a rough economic analysis is drawn, allowing to infer about the adopted efficiency measures impact.
\end{abstract}

Keywords-Artificial Neural Networks, Fuzzy Logic Control, Smart control

\section{INTRODUCTION}

A growing countries number are making an effort to implement new measures and policies to improve building energy consumption performance, but average energy consumption per person in the global buildings sector still remains practically unchanged since 1990. Thus, in order to improve global average energy use per capita, more building energy efficient measures are needed [1]. Also, recent data show that HVAC and lighting are responsible for $60 \%$ to $70 \%$ of building energy consumption, showing how important is to efficiently improve the control measures that are able to guarantee the appropriate indoor occupants' comfort with less energy resources [2, 3]. Lighting and luminosity control provide a better use of natural resources by maximizing natural light. It also controls the energy output to maintain luminosity in a certain set-point. Also, several studies have documented that in different countries, standby power losses show consumptions averages between $20 \mathrm{~W}$ to $90 \mathrm{~W}$ per home, representing $4 \%$ to $14 \%$ of total residential electricity use, achieving this value a major expression when related with office buildings $[4,5]$. The electrical energy price paid by the consumer to the distributor has an item that is directly related with the contracted power value. This value is chosen by the consumer and depends on the consumed power peak needed to maintain service continuity in the building. One way that allows to reduce the peak and consequently the energy cost is to use an energy storage system which automatically stores energy when it is cheaper. This system associated with renewable energy sources can highly reduce the amount of energy consumed from the power grid. Another viable option to reduce the energy consumption and improve the energy efficiency is replacing the obsolete appliances by "smart" ones. Smart appliances use modern technology supported by intelligent control solutions that can automatically process the task more efficiently and bring more convenience to people, which make them the tendency of future appliances [6]. Regarding the available control methods that can be adopted in building's energy management, the fuzzy logic approach offers a simpler, quicker and reliable solution showing clear advantages over conventional techniques [7]. Also, FLC offer easy implementation associated to precision and rigor, and requires mostly an able programmer to understand the problem and controller final objective [8]. Associated with the HVAC, FLC was implemented and an ANN was used as forecasting method providing to the HVAC controller the information about the outdoor temperature in the next hour. The forecast allows the system to pre-heat the house, increasing comfort and decreasing the power peak needed to reduce higher temperature gaps. ANN was chosen due to its ability to learn relation between inputs and outputs provided by the users, being and adequate and suitable solution for temperature forecast [9]. In this paper load control based in smart systems applied to individual control actions is presented in order to improve a house global energy management, showing that is an adequate solution supported by several FLC applied to: lightning control, luminosity control, i.e, blinds control, load control, HVAC control and storage system control. This approach defines a new algorithm that supports electrical energy efficiency aspects that can be improved in a house, such as the previously referred, HVAC, blinds, light and luminosity, standby energy, energy storage and appliances management. However, batteries life-cycles are not taken into account in the developed model. This paper is organized as it follows. In section II the house characterization is described and the load diagram is defined. In section III and IV are presented ANN and FLC models used in this paper. In section V the sub controllers that constitute the main controller are described. In section VI HVAC sub controller is presented. In section VI the HVAC model implementation results are addressed and overall results of other sub controllers' implementation are summarized. In section VIII the obtained results are discussed, and some future work direction is given. 


\section{HOUSE CHARACTERIZATION AND LOAD DIAGRAM}

The studied house has 2 bedrooms, 1 bathroom, 1 kitchen, 1 living room and 1garage. The space has $100 \mathrm{~m}^{2}$ and $2.5 \mathrm{~m}^{2}$ height. Constructive aspects, such as, the window area and thermal isolation define the equivalent house thermal resistance value. This value is calculated and set on the "Thermal model of a house" in the MATLAB toolbox. To measure house consumed energy it is necessary to know the equipment load profile and define its schedule. As an example, Fig. 1 shows a washing machine consumption profile.

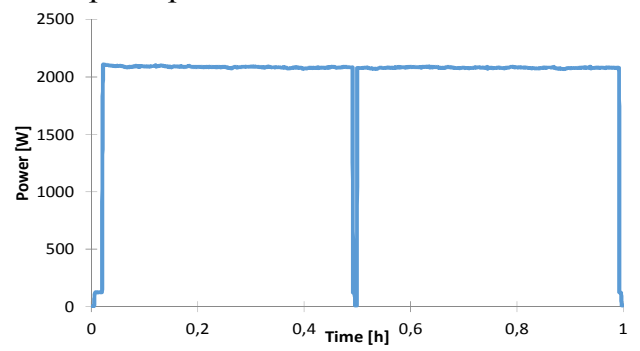

Fig. 1. Washing machine consumption profile

All equipment energy consumption sums accordingly to their schedule define the house's daily load diagram, as shown in Fig. 2. This diagram was built considering no energy efficiency measures.

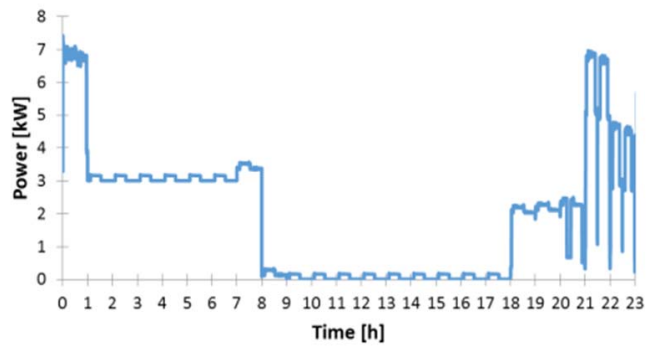

Fig. 2. Load diagram for a winter day

Analyzing the load diagram shown in Fig. 2, it is noticeable that consumptions peaks are higher than the other expected in normal off-peak hours (8:00-18:00). These consumption peaks, resulting from lightning, refrigerator, computer, dryer and also EV charging consumptions $(3 \mathrm{~kW})$, require a contracted power of $10,35 \mathrm{kVA}$ which highly affects the monthly final energy cost per kWh. However, these energy peaks may be reduced improving the load schedule during the considered day. Therefore, the implemented controller has the objective of reducing the average consumed energy and also the contracted power needed to guarantee the load demand.

\section{ARTIFICIAL NEURAL NETWORKS}

ANN are a common method for forecasting events using the historical relation between input and output data. One of the ANN architectures used to accomplish temperature forecast is the feedforward. The ANN forecast method is defined by three steps: The first step consists in learning phase. After, data is tested over and over until the variable's weight are determined, defining the training phase; The second step tests the performance of the network and insures that there is no loss of generalization. If a network is overstrained it should be trained again with a different number of neurons. This procedure defines the validation phase; In third step inputs given to the network are tested, allowing to calculate the error between the results given and the expected values. This defines the test phase. The relation between results and expected values used in this paper are calculated using Pearson's correlation [10].

$$
\operatorname{Correl}(r, s)=\frac{\sum(a-\bar{a})(b-\bar{b})}{\sum(a-\bar{a})^{2}(b-\bar{b})^{2}}
$$

Where "a" and "b" are a set of values, $a^{-}$and $b^{-}$are respectively, the set samples mean value. Pearson's correlation can retrieve different values, if the result is close to 1 the correlation is positive and strong, if is 0 the results are completely random and if is close to -1 the correlation is strong but negative.

\section{FUZZY LOGIC CONTROL}

The control using fuzzy logic concept was introduced with the objective of solving vague or uncertain problems. The uncertain character presented by events is named fuzzy character [8]. FLC requires the implementation of fuzzy sets characterized by generalization of the classic set concept. This generalization allows the sets to incorporate the fuzzy character. Even though, the fuzzy sets theory being used in problems characterized by vague events, allows a precise and rigorous resolution. The programmer needs to define a universe of discourse $U$, which represents the domain of a certain variable. Each fuzzy set, F, can be represented in $U$ as a set of ordered pairs of a generic element $u$ and its degree of membership, given by (2).

$$
F=\left\{\left(u, \mu_{F}(u)\right) \mid u \in U\right\}
$$

If $\mathrm{U}$ is continuous, $\mathrm{F}$ can be written as (3).

$$
F=\int \frac{\mu_{F}(u)}{u} d u
$$

If $\mathrm{U}$ is discrete, $\mathrm{F}$ can be written as (4).

$$
F=\sum_{i=1}^{n} \frac{\mu_{F}\left(u_{i}\right)}{u_{i}}
$$

Where in (2-4) $\mu_{F}$ represents the membership function and $i$ and $n$ are generic variables. In all implemented controllers, the "and" and "or" operators are used. All FLC have the following characteristics: Mandani as Inference algorithm, centroid as defuzification method, "and" method is minimum, "or" method is maximum, aggregation method is maximum and implication method is minimum. When testing a certain event, the FLC tests all the rules and uses the aggregation method to unite all the fuzzy sets resultant from the rules application. The max method is used and the defuzzification method is center of area (COA).

\section{CONTROLLERS - FEATURES AND OPERATION}

The smart controller is responsible for the equipment management and energy efficiency improvement and consists in four sub controllers, as shown in Fig. 3. All sub controllers use FLC to automatically manage the equipment. The ANN are used to forecast the outdoor temperature in the HVAC control. The lighting and luminosity control associate the blinds opening or closing with the lamps output power management. This means that the natural lighting usage is maximized, and the electric 
energy used by artificial lighting is minimized, assuring simultaneously that the overall illuminance is the desired one. This controller relates the time of the day with the inside house luminosity to determine the lamps power output.

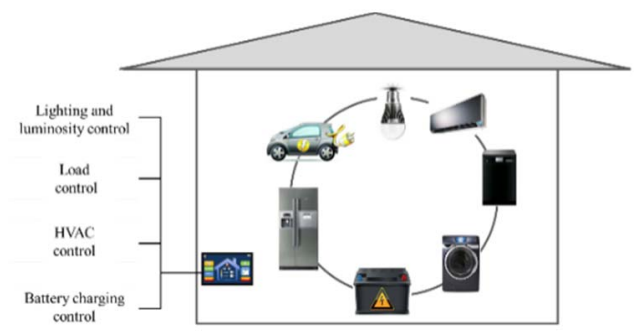

Fig. 3. Smart controller scheme

The same FLC also uses the day time as input and relates it with the blinds position, in order to decide if they should open, close or maintain position. The second sub controller is responsible for managing the equipment connected to the grid and decides if they are being used or just consuming energy passively, i.e, determine if this equipment are in standby. This management requires the support of smart plugs, because enables knowing the energy consumption of any equipment in real time. The controller was programmed to use information provided by the smart plug and after 30 s, and if the energy consumed is equal or lesser then $7 \mathrm{~W}$ the plug is turned off. Otherwise, means that the equipment is actively being used and consequently the plug is not disconnected. Therefore, the controller relates both inputs, time and consumed energy, and decides to keep connected or to disconnect the plug from the grid. The HVAC controller is adapted from the MATLAB toolbox "Thermal model of a house", allowing to determine a room inside temperature accordingly to the equivalent thermal resistance, the room outside temperature, the inside room temperature and decides if the HVAC needs to be turned on or not, by using a relay as a thermostat. The developed HVAC FLC uses the number of people inside the house and indoor temperature as inputs and determines how much thermal energy is needed to heat or cool the building. A detailed analysis of HVAC controller design is addressed in Section VI. The battery charging sub controller is designed considering the existence of photovoltaic solar panels as another energy source. According to the day time and batteries charge state, the developed FLC decides if the batteries charges from the power grid or from photovoltaic panels. This sub controller was designed to maximize the renewable energy storage and if necessary, to fulfill the remaining storage space using energy from the power grid, when the energy price is cheaper. The usage of stored energy is schedule accordingly to the habitants consumption needs, focusing simultaneously in reducing the energy consumption peaks, resulting in a lower contracted power and consequently, contributing to an energy bill reduction.

\section{HVAC CONTROL}

As mentioned in Section I, in buildings, the HVAC system is one of the equipment with higher energy consumption, thus, is it relevant to pursue new to control methods to improve its efficiency. The developed HVAC control system uses as inputs, the number of people inside the house, the heat released by habitants from their daily activities and the outdoor temperature given by the ANN, as shown in Fig. 4.

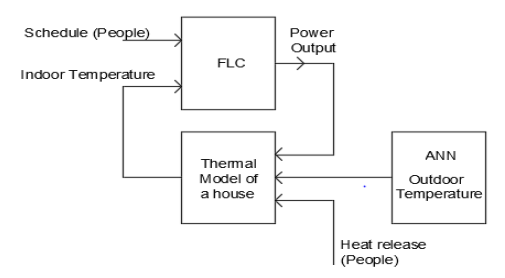

Fig. 4. HVAC control scheme

A number of people inside the house schedule at a certain day time is used to control the HVAC pre-heating, since it starts one hour before the house occupancy. Additionally, it is also provided to the system the number of expected people, and consequently their contribution to the indoor temperature increase. The second output, related to the heat release, considers that, in average, people release approximately 150W (500 $\mathrm{Btu} / \mathrm{h})$. This value represents an approximation shown in [11], since it is not predictable what activities habitants will perform during day time. The people heat released also depends on body size, in this case, it is considered the DuBois area with is $1.8 \mathrm{~m}^{2}$ (a calm person with the DuBois area releases 1 met per hour, in thermal energy) $[11,12]$. In order to improve HVAC controller accuracy, equipment able to detect entrances is used, avoiding the error occurred due to daily routine changes. This allows turning off equipment when no entrances are detected. The last HVAC controller input is outdoor temperature and is the one that mostly influences the indoor temperature being highly dependent on the house insolation. Because of that characteristic, it is relevant to forecast the outdoor temperature, in order to provide global control system improvement. Therefore, in this paper, the outdoor temperature is forecasted resorting to ANN. The used ANN is feedforward, with four inputs that represent the temperature in the previous four hours, and the output is the temperature an hour before the habitants' occupancy. For ANN training twenty neurons were used, and the Levenberg-Marquardt training algorithm was chosen. The training set is constituted by temperature values of 2010 Winter. The developed ANN representation is shown in Fig. 5.

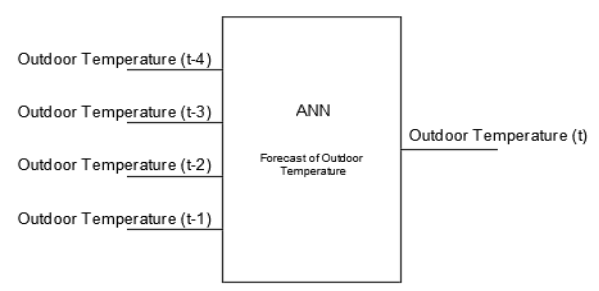

Fig. 5. ANN- Forecast of outdoor temperature

In this $\mathrm{ANN}$, the data used has an autocorrelation higher than 0.98 , which indicates a deviation of less than $2 \%$, when comparing the forecasted values with the expected ones. The ANN input data was given in matrix format [182×4], where the first value represents the number of days between October and March and the second value represents the hours. There were used four hours because these are the ones that most influence the fifth hour. The ANN performance can be evaluated using the mean square root (MSE) or the mean absolute percentage error (MAPE). The MSE is given by (5). 


$$
M S E=\sqrt{\frac{1}{n_{d}} \sum_{k=1}^{n_{d}}\left(\hat{Y_{k}}-Y_{k}\right)^{2}}
$$

Where $n_{d}$ represents the number of data, $Y_{k}$ the forecasted values and $Y_{k}$ the real values. The MAPE is given by (6).

$$
M A P E=\frac{100}{n_{d}} \sum_{k=1}^{n_{d}}\left|\frac{Y_{k}-\hat{Y}_{k}}{Y_{k}}\right|
$$

When trained with different numbers of neurons, the chosen ANN presented MSE values between 0.56 and 0.61 for the training, validation and test phases, being this ANN the one that presented better results. The resulted outdoor temperature is used as an input of the house thermal model given by [13]. This model considers that the energy flow from the HVAC system to the room is given by (7).

$$
\frac{d Q_{H V A C}}{d t}=\left(T_{\text {out }}-T_{\text {rooom }}\right) \cdot \text { Mdot. } c
$$

Where $d Q_{H V A C} d t$ represents the energy flow from the HVAC to the room, $T_{\text {out }}$ represents the temperature of the HVAC blown air, $T_{\text {room }}$ is the room temperature, $M d o t$ is the air mass flow and $c$ is the air heating or cooling capacity at constant pressure. The temperature inside the room is given by (8).

$$
\frac{d T_{\text {room }}}{d t}=\frac{1}{M_{\text {air }} \cdot c}\left(\frac{d Q_{H V A C}}{d t}-\frac{d Q_{\text {losses }}}{d t}\right)
$$

Where $d T_{\text {room }} / d t$ is the room inside temperature variation, Mair is the air mass, $d Q_{\text {losses }} / d t$ is the energy lost from the interior to the exterior. The thermal energy exchanges between indoor and the outdoor are highly dependent from the isolation represented in this model by the equivalent thermal resistance, $\mathrm{R}_{\mathrm{eq}}$. The losses are also calculated by (9).

$$
\frac{d Q_{\text {losses }}}{d t}=\frac{T_{\text {room }}-T_{\text {out }}}{R_{\text {eq }}}
$$

The equivalent thermal resistance depends on building constructive characteristics. This value is calculated as described in [13] and given by (10).

$$
R_{e q}=\frac{R_{\text {walls }} \cdot R_{\text {windows }}}{R_{\text {walls }}+R_{\text {windows }}}
$$

Where, $R_{\text {walls }}$ and $R_{\text {windows }}$ are respectively, the walls and windows equivalent thermal resistances. Because thermal model determines the expected indoor temperature values, to improve controller's accuracy these temperatures are used in parallel with the information about the schedule and amount of people inside the building. This information is used as inputs of the implemented FLC and the corresponding output is given by the HVAC power output, as shown in Fig. 6.

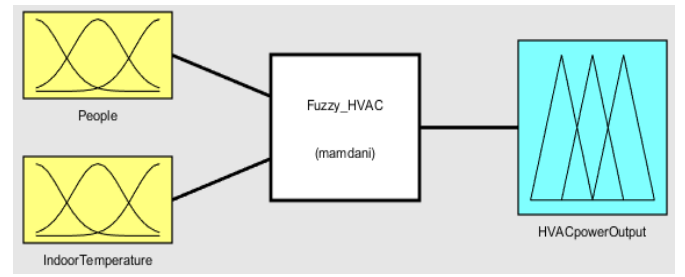

Fig. 6. FLC HVAC controller
In Fig. 4 can be seen that HVAC power is used as an input of the thermal house model (referred as power output), acting as a system retroaction allowing adjusting the indoor temperature until the desired set-point is reached. The information about the amount of people inside the house allows the system to determine the HVAC power output deliver considering the people heat released. This variable universe of discourse is $[0 ; 20]$ with six membership functions as shown in Fig. 7.

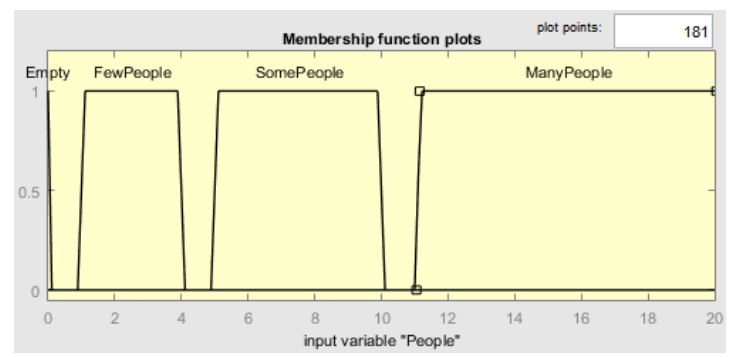

Fig. 7. HVAC controller input - "People"

The second input variable "IndoorTemperature" is responsible by the HVAC control and determines the equipment state, i.e., heating, cooling or turned off. This variable also defines the set-point value and the grade of membership. Thus, if the temperature is close to the set-point, the HVAC begins to reduce the generated thermal power or turns it off, allowing to decrease the consumed energy. On the other hand, if the temperature moves away from the set-point, the membership function returns the value " 1 " and the HVAC increases the heating/cooling power value. The "IndoorTemperature" variable has a universe of discourse between $[0 ; 40]$ and it is characterized by three membership functions as shown in Fig. 8. The output variable defines quantitatively the needed power in Btu to reach the set-point. This variable limit is defined by the HVAC equipment [14] and in this particular case is defined by the heating power of $29300 \mathrm{Btu}$, and cooling power of $23900 \mathrm{Btu}$.

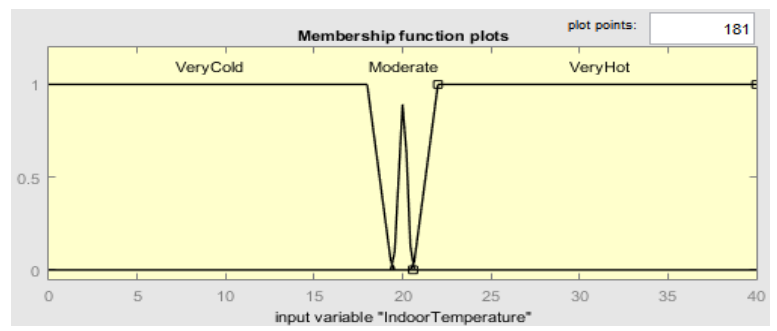

Fig. 8. HVAC controller input - "IndoorTemperature"

These specifications characterize the variable universe of discourse, where positive values represent heating and the negative represent cooling. There were used seven membership functions as presented in Fig. 9.

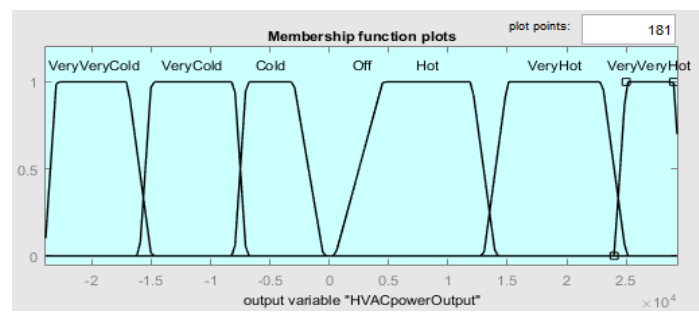

Fig. 9. HVAC controller output - "HVACpowerOutput" 
After the variables fuzzification it is necessary to define the FLC control rules, as presented in Table I.

TABLE I. HVAC CONTROLLER - RULES

\begin{tabular}{|c|c|c|c|c|}
\hline \multirow{2}{*}{$\begin{array}{l}\text { HVAC } \\
\text { Power }\end{array}$} & \multicolumn{4}{|c|}{ Indoor Temperature } \\
\hline & & VeryCold & Moderate & VeryHot \\
\hline \multirow{4}{*}{ 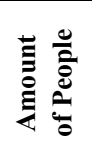 } & Empty & Off & Off & Off \\
\hline & FewPeople & Hot & Off & Cold \\
\hline & SomePeople & VeryHot & Cold & VeryCold \\
\hline & ManyPeople & VeryVeryHot & Cold & VeryVeryCold \\
\hline
\end{tabular}

From Table 1 can be obtained rules like: "If the amount of people is Empty and the indoor temperature is VeryCold then the HVAC is off."; "If the amount of people is SomePeople and the indoor temperature is VeryHot then the output power is VeryCold". Due the implemented control rules, the system only works when established and using different power stages, providing an energy consumption reduction.

\section{RESULTS}

To test the HVAC controller, it is consider a winter scenery. The time operation is defined between $5 \mathrm{pm}$ and $11 \mathrm{pm}$. The indoor temperature is $15^{\circ} \mathrm{C}$ and the outdoor temperature stays around $10^{\circ} \mathrm{C}$, when the system is turned on. Also is considered four people inside the house, each one releasing approximately $150 \mathrm{~W}$ (500 Btu). The indoor temperature is shown in Fig. 10.

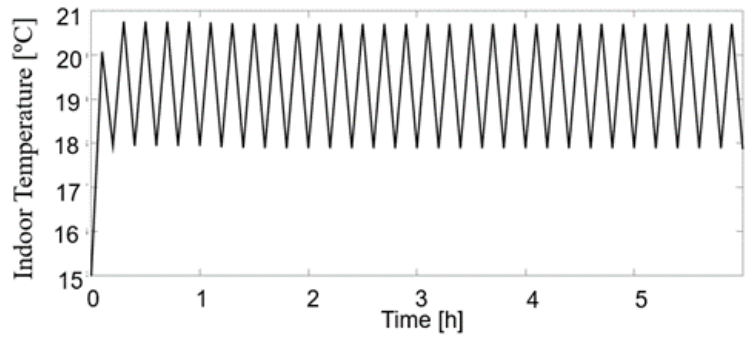

Fig. 10. HVAC results - Indoor Temperature

Analyzing Fig. 10 is it noticeable that this representation corresponds to a heating scenery, which means that the temperature increases until it reaches the set-point's lower limit and after that it stays around it. In a cooling scenery the same occurs, but in that case the temperature will be settled around the upper limit. The indoor temperature variation is proportional to the HVAC power output as shown in Fig. 11, which for worst case scenario was defined to work at rated power, resulting in the observed sawtooth signals.

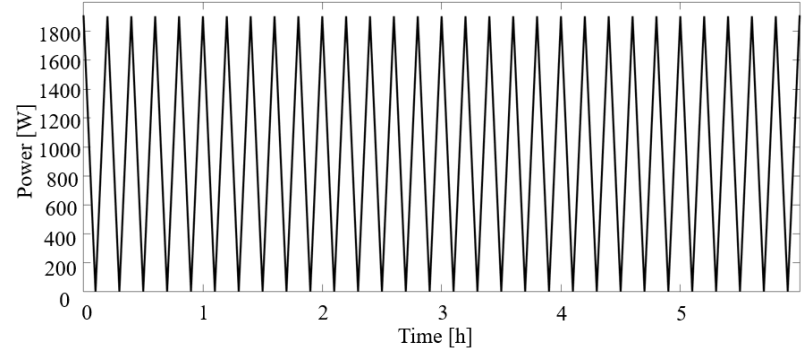

Fig. 11. HVAC results - Power output
From Fig. 11 analysis it is possible to conclude that when the indoor temperature is around the set-point the HVAC system reduces the thermal power output until the temperature reach again the set-point's lower limit. The sum of all consumed energy in the six hours of operation is multiplied by 0.1942 $€ / \mathrm{kWh}$, which is the energy cost in a winter period for a contracted power of $10.35 \mathrm{kVA}$. The result is presented in Fig. 12. The implemented HVAC system resulted in a cost of $0.78 €$ for six operation hours. The model implemented with the intelligent system controller shows more energy and money savings when compared to the HVAC system model without controller, which maintains the maximum power output until the set-point is reached.

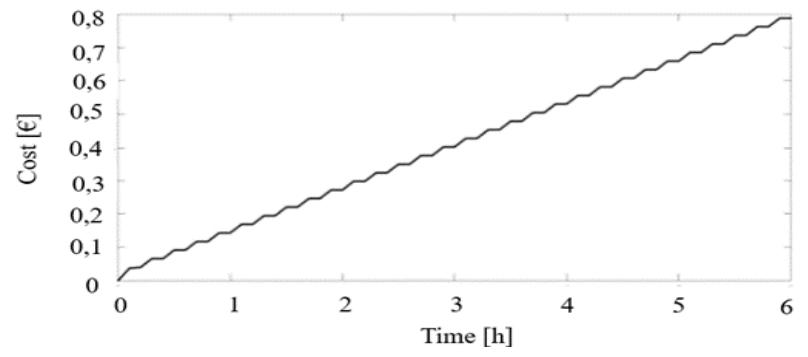

Fig. 12. HVAC results - Energy cost

The performed indoor temperature adjustments made by the intelligent system controller, not only offer extra comfort but also contributes for a costs reducing in $35 \%$, as shown in Table II.

TABLE II. HVAC SAVINGS

\begin{tabular}{|c|c|}
\hline Model & $\begin{array}{c}\text { Cost } \\
\text { (6 months) }\end{array}$ \\
\hline HVAC without controller & $157.1 €$ \\
\hline HVAC controlled by an intelligent system & $102.0 €$ \\
\hline
\end{tabular}

The other FLC implemented resulted on the savings presented in Table 3, considering a comparison between these values and the same scenery applied to a building without energy efficiency measures (Fig. 2). For the "Incandescent and fluorescent to Led" results the saving occurred by replacing the incandescent and fluorescent lamps for LED lamps. The lighting and luminosity control scenery considers that one hour of artificial lighting is replaced by natural lighting and that in the next considered hour, the lamps are with $50 \%$ of the maximum power output. The implemented load control methodology considers that the controller eliminates the stand-by energy consumption turning off the equipment that are consuming less than $7 \mathrm{~W}$

TABLE III. PERCENTAGE OF OVERALl ENERGY SAVINGS

\begin{tabular}{|c|c|}
\hline Applied measure & Energy Savings \\
\hline Lighting change to LED & $84 \%$ \\
\hline Lighting and luminosity control & $71 \%$ \\
\hline Load control & $100 \%$ \\
\hline Renewable Energy and Storage control & $72 \%$ \\
\hline
\end{tabular}


The renewable energy and storage controller resulted in $72 \%$ savings when the grid's energy is replaced by the photovoltaic energy stored during day time. However, because the batteries life-cycle are not considered in the developed model, the energy savings observed in Table III don't take into account the energy management needed to support a more efficient energy storage system management. For energy savings calculation the energy consumption is calculated with and without energy efficiency measures, subjected to a cost of $0,1942 € / \mathrm{kWh}$. Energy saving results derive from the difference between these two calculi. These FLC implementation not only reduce the spent energy through energy efficiency concept $[15,16]$, "use less energy to obtain the same service", but also turns possible a contracted power reduction from $10.35 \mathrm{kVA}$ to $6.9 \mathrm{kVA}$ through the storage system integration which resulted on a $26.3 €$ saved every six months. These adopted measures allowed to change energy price tariff from the traditional one to time-of-use rate, accordingly to the Portuguese energy policy [17] resulting on $26.4 €$ saving in the considered time frame. This reduction occurs because the power grid regulator offer benefits to consumers that use energy in off-peak periods. This was possible because the storage system was schedule to charge using renewable energy sources during peak periods or using energy from the power grid during off-peak periods.

\section{VIII.CONCLUSIONS}

This paper shows that the implementation of FLC and ANN in systems, with the objective of reducing the consumed energy is viable. In addition is shown that these systems are dynamic and they can be adjusted to fit the needs and overcome the restrictions provided by users. The usage of linguistic variables in FLC makes it an intuitive control system, and the programmer experience contributes to an efficient and accurate controller performance when associated with an appropriated chose of variables and corresponding membership functions. It is verified that the implemented ANN is a reliable forecasting method, showing $2 \%$ deviation between the resulting forecasted values and expected values. The storage capacity enables the system to consume energy in off-peak periods and maximize the photovoltaic energy usage, resulting in a less exigent load diagram. This not only represents lower energy peaks consumption in the most expensive periods, but also allows the consumer to contract less power to the energy distributor, decreasing the charges associated to this term, in the monthly energy invoice. This paper shows that load control based in smart systems applied to individual control actions allow to improve global energy management in a house. Also, if consumer adopts energy efficiency measures, by replacing non efficient appliances by equivalent and more efficient ones, reducing standby consumption and improving HVAC control system, a significant energy cost reduction can be achieved. This study considers more economic controllers when compared with the already existing ones and an EV charger with is in line with nowadays environmental concerns and polices. There are other important but residual measures that contributes for energy savings, namely led light and turning off equipments, reducing standby power consumption. However, a more detailed economic analysis of the implemented system in intended to be addressed in future work developments.

\section{REFERENCES}

[1] IEA. International Energy Agency, “Tracking Clean Energy Progress 2017 Energy Technology Perspectives 2017 Excerpt Informing Energy Sector Transformations", 2017 Report.

[2] L. Pérez-Lombard, J. Ortiz, J. Pout, "A review on buildings energy consumption information”, Energy Build, 40, n.3, pp. 394-398, 2008.

[3] D. Ürge-Vorsatz, L. F. Cabeza, S. Serrano, C. Barreneche, K. Petrichenko, "Heating and cooling energy trends and drivers in buildings". Renew Sustain Energy Rev 41(0):85-98 2015.

[4] P. S. Solanki, V. S. Mallela, and C. Zhou, "An investigation of standby energy losses in residential sector: Solutions and policies", International Journal of Energy and Environment, voI. 4. no. 1. pp. 117-126. 2013.

[5] Z. Wei, Y. Zhang, F. Jin, W. Yin, L. Wu, "Standby power consumption estimation for energy saving service", in: Proceedings of the 2014 IEEE International Conference on Service Operations and Logistics, and Informatics (SOLI), 2014, October, pp. 16-21.

[6] P. Cui, L. Feng; P. Xun, P. Zhu, "Load Scheduling of Thermostatical House-Hold Appliances Against Abrupt Changes in Smart Grid", 10th International Symposium on Computational Intelligence and Design (ISCID), Vol: 1, Pages: 470 - 475, 2017.

[7] F. Chekired, M. Achour, S. Zoubeyr, C. Madjid, G. Abderrezak, A. Meflah. "Fuzzy logic energy management for a photovoltaic solar home". Energy Procedia. 2019. 134. 723-730. 10.1016/j.egypro.2017.09.566.

[8] Y.Y. Ghadi, M. Rasul, and M. Khan, "Design and development of advanced fuzzy logic controllers in smart buildings for institutional buildings in subtropical Queensland.”, Renewable and Sustainable Energy Reviews, 2016. 54: pp. 738-744.

[9] R. M. Yedra, F. R. Díaz, M. M. C. Nieto, M. R. Arahal, "A Neural Network Model for Energy Consumption Prediction of CIESOL Bioclimatic Building", Proceedings of International Joint Conference SOCO'13, pp. 51-60, Salamanca, Spain, September, 2013

[10] R. Pereira, "Redes Elétricas Inteligentes", PhD Thesis (in portuguese) 2015.

[11] I. Edition, 2009 Ashrae ${ }^{\circledR}$ handbook, vol. 30329, no. 404. 2009.

[12] C. U. Ergonomics, "Ambient Environment: Thermal Conditions." [Online]. Available: http://ergo.human.cornell.edu/ [Accessed: 28-May2019].

[13] I. The MathWorks, "Thermal Model of a House." [Online]. Available: https://www.mathworks.com/help/simulink/examples/thermal-model-ofa-house.html. [Accessed: 17-Jan-2017].

[14] Samsung, "Multi Sistema- Unidade Interior." [Online]. Available: http://www.samsung.com/pt/business/business-products/system-airconditioner/doméstico-multi-sistema/AJ070MCJ4EH/EU. [Accessed: 12-Aug-2019].

[15] B. Omarov, A. Altayeva, Z. Suleimenov, Y. I. Cho and B. Omarov, "Design of Fuzzy Logic Based Controller for Energy Efficient Operation in Smart Buildings," 2017 First IEEE International Conference on Robotic Computing (IRC), Taichung, 2017, pp. 346-351.

[16] G. Yazeed, "Energy Performance of Fuzzy Logic Controllers in Smart Buildings". International Journal of Energy Economics and Policy. Vol 9, No 1, 2019, pp. 41-47.

[17] EDP, Energy Price Tariff (in Portuguse) http://www.edpsu.pt/pt/particulares/tarifasehorarios/BTN/Pages/Tarifas BTNate20.7kVA.aspx [Accessed: 13-Aug-2019]. 